\title{
Medical Product Shelf Life
}

National Cancer Institute

\section{Source}

National Cancer Institute. Medical Product Shelf Life. NCI Thesaurus. Code C70855.

The period during which a medical product retains its properties and stated performance within specified limits throug hout its shelf life if stored under defined conditions. The stability period is determined from the date the product was manufactured. After the end of the product shelf life it is not to be used. The chemical, physical and microbiological aspects of stability are to be considered for a medical product according to 21 CFR Part 211 GMP. 